\title{
Digital asset management in advertising agencies
}

\begin{abstract}
Tony McCarthy
is the Director of Worldwide Technical Sales of Xinet, Inc. He has been involved with the development and execution of digital asset management systems for 12 years. Tony has spoken on digital asset management at Graph Expo, Seybold New York, Seybold San
\end{abstract} Francisco and PrintMedia MagazineTech in New York, and has been widely quoted in publications.

\section{Keywords: advertising agencies, DAM, speed-to-market, profit centers}

\begin{abstract}
This paper reviews how some advertising agencies in the USA and Europe Ogilvy, McCann Erickson, Grey Worldwide, BBDO, Leo Burnett Worldwide, Euro RSCG, Publicis' Capps Digital and TracyLocke - chose and implemented a flexible, scalable digital asset management (DAM) system that allows them to collaborate via the internet with hundreds of agency offices and clients, worldwide. Executive, creative and production people from each ad agency describe how they approached their return on investment (ROI) research before choosing their DAM solution, and how they implemented the solutions to deliver lucrative business results. Agency staff explain how a coherent DAM system allows advertising agencies to do more work with fewer staff by ensuring speed to market, productivity savings, increased agency and client revenues, secure client branding and a 24-hour art studio. The paper also tells readers how to handle the critical issues of file-naming criteria, load balancing and ensuring a cultural buy-in within the agency.
\end{abstract}

\section{INTRODUCTION}

In the last decade, most advertising agencies recognized the need for a coherent digital asset management (DAM) system and many implemented solutions to best meet their requirements.

As the number of assets grew, and many agencies consolidated into much larger organizations, however, the need for more flexible, scalable and accessible asset management solutions became very apparent.

The following is a review of how some agencies in the USA and Europe - Ogilvy, McCann Erickson, Grey Worldwide, BBDO, Leo Burnett Worldwide, Euro RSCG, Publicis' Capps Digital and TracyLocke chose and implemented a DAM system that works, that grows and that allows the agencies to link up hundreds of offices and clients, worldwide.

\section{THE TIME TO UPGRADE}

Recognizing the need to "know where everything is," McCann Erickson implemented their asset management strategy seven years ago with Canto's Cumulus.
However, as the number of McCann's assets grew beyond two million, "the system ground to a halt," said McCann Erickson's New York Senior Vice President, Brad Mintz. ${ }^{1}$

While researching their options for a replacement system, McCann identified a solution that would return many thousands of dollars in savings and new revenues. Launched on 1 January 2005, the new DAM system connects 120 people in the prepress studio and creative departments of McCann Advertising and McCann Relationship Marketing, and will ultimately link all McCann offices worldwide.

"Xinet's WebNative is, in my opinion, the de facto standard for doing digital asset management at ad agencies," Mintz said.

\section{NEED FOR SPEED TO MARKET}

What drives the push for more effective DAM systems at ad agencies is the need for speed in highly competitive industries.

Research by GISTICS Incorporated, an Oakland-based research firm, indicates that speed and coordination in the creation and distribution of marketing content leads to successful new product campaigns. ${ }^{2}$ And any increase in the 


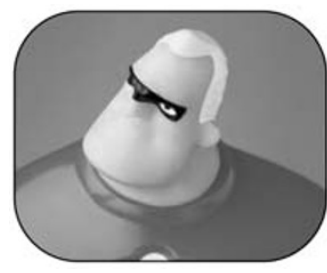

Figure 1: "Mr Incredible" from the popular film "The Incredibles" is an image from a McDonald's campaign through Europe time to market - if only by a few days — can mean increased sales.

"Speed to market and real-time marketing is where you need to be right now in the advertising industry," said Fred Squeo, Partner at TracyLocke, the agency of record for Pepsi International and Grand Marnier.

"Your client is always challenging you to do things efficiently, and to explain where their marketing budget is being spent, and is it to the greatest effectiveness. We knew we had to have the technology to help us get there," said Squeo, who uses DAM to create and host all the advertising and promotional assets for Pepsi International and Grand Marnier.

Like McCann Erickson and all the agencies mentioned here, the solution used by TracyLocke is Xinet's WebNative, which provides web-based, 24/7 access to live and archived files, and significant image and layouthandling functionality. Figures 1-9 in this paper are images created and distributed by advertising agencies using WebNative, Xinet's DAM solution.

Without leaving their common work environment, people can contribute to the back-end systems, such as designers accessing low-resolution images through a web interface. The solution creates a transparent workflow by not changing the workflow already in place.

"DAM gives our clients speed to market because it cuts down time during the creation and approval process," said Chris Formisano, Vice President Associate Creative Director at Euro RSCG in Wilton, CT. "The bigger the

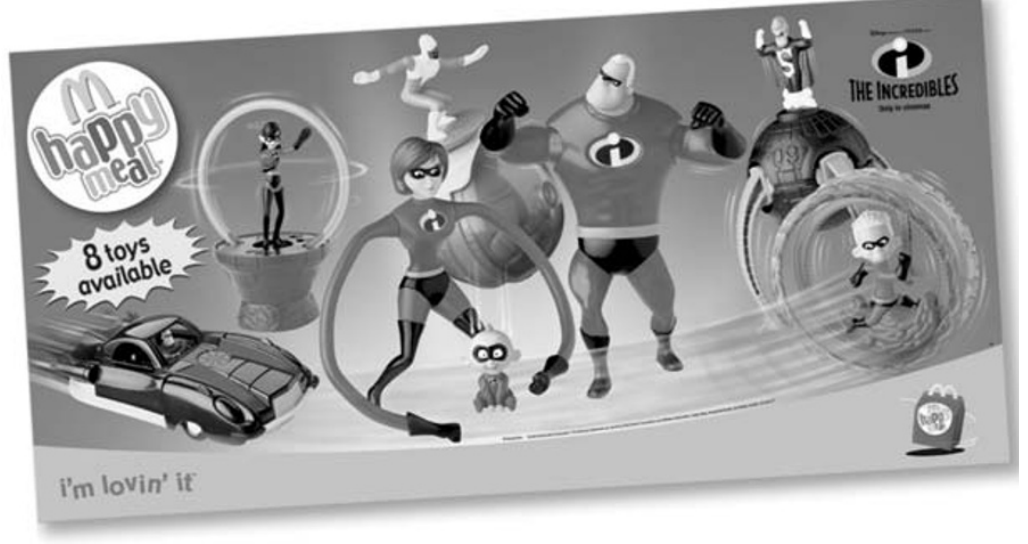

Figure 2: Digital asset management ensures that advertising agencies can provide their clients global branding, speed to market and real-time marketing business, the more levels of bureaucracy that slow down the approval process. Now the process is more active because everyone has access to the system from any web browser."

\section{MONEY}

Of course nothing spurs action like a Chief Financial Officer recognizing a huge monetary windfall.

"When I did the calculation on productivity savings with our new DAM workflow system, the numbers were so astronomically high, I was afraid to present them. I had to dumb them down," said McCann's Mintz, who spent months studying every DAM solution on the market and possible workflows of how his agency would use the new system.

"I based the ROI on little calculations of how much you're going to save on this task and that task, equating time to dollars. When you deal with a formula like that, the savings can be huge in terms of productivity. And when you add in client cost savings and additional revenue from new services, the figure is even higher," Mintz said.

In other words: time is money, says Chris Carlock, Infrastructure and Workflow Engineer at Publicis' Capps Digital.

"The quicker we can get this stuff, the more we save because we pay overtime. If you can grab assets off the system or server quickly, and it saves five minutes from each worker's day every day, those five minutes mean you are saving a tremendous amount of money," Carlock said.

\section{HOW THEY DO IT}

\section{McCann Erickson}

As the agency of record for Microsoft, McCann Erickson uses its new DAM solution to distribute all the assets and ads for Microsoft to 60 different McCann Erickson and McCann Relationship Marketing offices used worldwide.

"When it's four in the morning here and someone in China needs an image for an ad, I don't need to worry about having someone here to make that image," said Warren Vegas, Vice President of Production Services for McCann San Francisco. "It's a 24-hour facility without having to staff it 24 hours a day." 


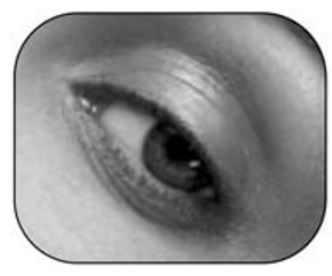

Figure 3: Images placed in a DAM database ensure colour standards and accuracy
Every image placed on the DAM database and distributed to each country includes information on how the files should be used, color conversion information, color standards for Asia, Europe and USA, and SWOP Toyo in the Euroscale.

"All these asset management modules allow the studio and production teams to be more efficient when finding files we're working on, finding the right version, and distributing them to creatives as they're needed - without mistakes," Vegas said.

\section{Ogilvy London}

Ogilvy London uses its DAM solution to manage the brands of blue-chip clients such as Castrol and Unilever, and to collaborate with Ogilvy offices in 106 countries.

Running off Ogilvy's server at the London hub office, images and brands are accessed securely from any location worldwide beyond the firewall.

"Through a series of customized websites designed for each client and product, art directors approve shots, images, brands, and layouts wherever they are in the world,' said Iain Seers, Director of Ogilvy London's CreativeSystems group. "For file delivery, our system allows us to reach our 26 markets and 50 offices across Europe alone, quickly and reliably, eliminating both the hard and soft costs of ordering, burning, amending and delivering artwork CDs."

"The ROI on the software itself was paid off within three months," Seers said. "When you factor in expense of the platform, it was covered within a year."

\section{BBDO}

Since implementing an organized DAM system in their New York office, BBDO is doing twice the amount of work with two less people.

"That's based solely on our DAM organization," said Jd Michaels, BBDO's New York Vice President Director of Graphic Services. "Before DAM, searching for a file was akin to an 'X-Files/ Indiana Jones' scene. Remember that room at the end of 'Raiders of the Lost Ark'? That was our DAM system."

The first thing Michaels did when he arrived was install two enormous blackboards in his office.

"The best DAM systems are visual. Art directors think in a visual way. If you try to explain something to them and talk about numbers or concepts, all you get are puzzled expressions. But if you go to the blackboard and show them, the light bulbs go on. The light bulb DAM solution is the one that shows me, it doesn't tell me," Michaels said.

Days after implementing its new DAM system, BBDO used it to solve a colossal problem: One giant client had a worldwide shoot scheduled for $5,000+$ final photos from eight countries with eight different languages, and wanted every image processed through the New York office.

"It worked perfectly. The photographers shot digitally. We gave each of them an uploader for their desktops with their names on them so they could drag and drop their images 24 hours a day. When the New York office woke up, there were 5,500 final shots awaiting them that were uploaded while we slept.

When our creatives came in to review them, we said: 'Click here. These are all your pictures.' When the client came in, they were expecting reams of paper photos taped up on the wall, but instead we used the DAM system to project

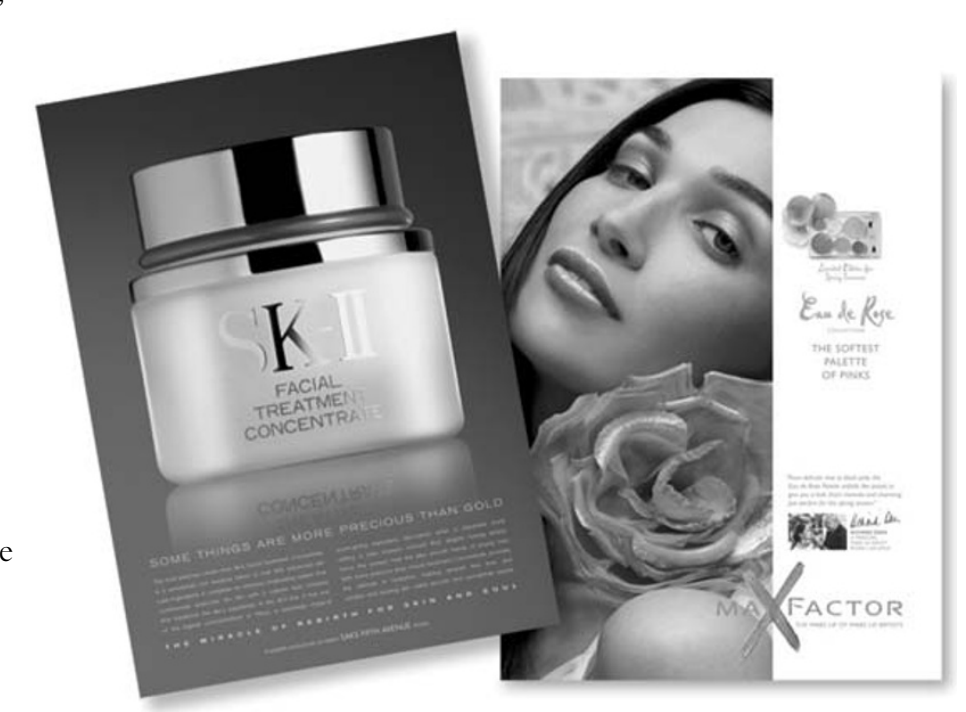

Figure 4: WebNative enables ad designers to access low-resolution images through a web interface 


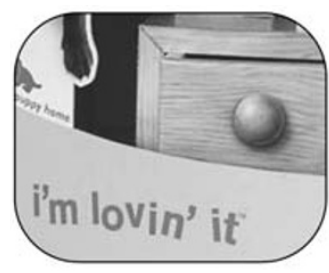

Figure 5: DAM gives large corporations like McDonald's secure brand management them as a medium. Then we gave them a web address so they could review it at home if they wanted," Michaels said.

This underscores the central misconception of asset management, Michaels says. "It's not a library function. It's a dynamic active database tool designed for problems like this."

\section{Leo Burnett Worldwide, London}

For Stars Digital, Leo Burnett Worldwide's inhouse digital studio in London, installing a DAM system six years ago was instrumental in adding to the agency's client roster of corporate big hitters, which includes Coca-Cola and Kellogg's.

Stars Digital uses its DAM solution to work on the production of mechanicals for McDonald's Happy Meal boxes, which go out to 46 different markets and can range up to $2 \mathrm{~GB}$ in file size.

DAM also translates into savings for Stars Digital because the customers access their files via the internet, eliminating all courier charges during the creation and approval process.

"Our system is reliable and straightforward for our clients to use. Normally we can have them set up within five minutes to use their own customized image banks," said Dave Ewers, Systems Manager at Stars Digital. "And the 13 built-in languages that come out of the box with the system are really useful because we host sites for clients in a number of European countries."

\section{Grey Worldwide}

Grey Worldwide's New York office turns out ads for billboards, print, magazine, newspapers and the web with remarkable speed, thanks to its DAM system.

For example, a recent job for Grey's client Canon, a photo spread from the Indianapolis Speedway, appeared in a magazine one day after it was photographed.

"After we upload the files, art directors look at them online without having to download the whole high-resolution file. Then we can pass it to whatever vendor needs to see the ad, then send it to the magazine itself within hours," said
Graeme Thomson, who works in Grey's art studio and graphics services department in New York.

Grey also uses its DAM system to automate and simplify PDF creation and printing.

"PDF creation is an important thing for an ad agency, because a lot of our type proof or replacement proof work goes back and forth to the client in PDF form," Thomson said. "By centralizing it with our DAM system, we have one way of making a PDF. We don't have different people with different settings making different types of PDFs at different resolutions. And we're not wasting bandwidth, sending files to the client."

\section{Publicis' Capps Digital}

Since implementing a DAM system, Publicis' Capps Digital has eliminated an entire department within its agency, the archiving group, which had two full-time employees and one part-time person.

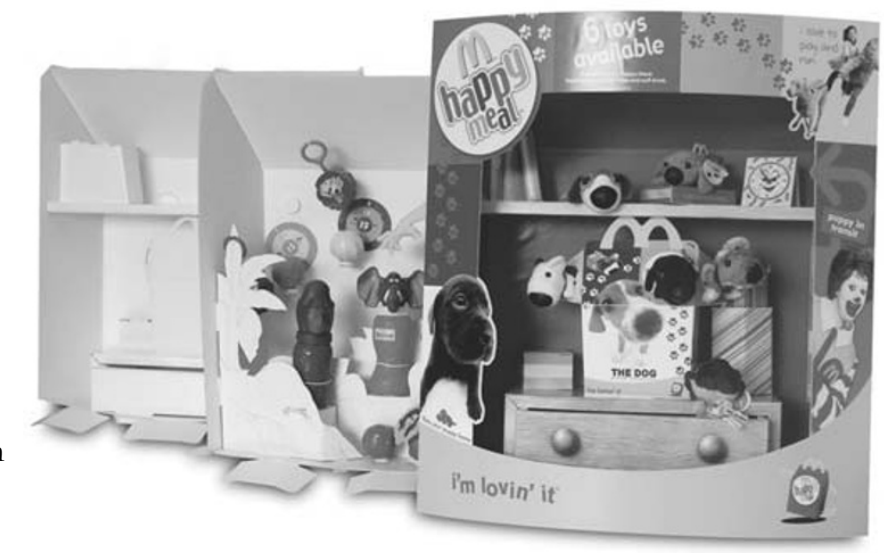

Figure 6:

Leo Burnett's Stars Digital uses Xinet's WebNative to work on the production of mechanicals for McDonald's Happy Meal boxes, which go out to 46 different markets and can range up to $2 \mathrm{~GB}$ in full size

"We've gained the ability to un-archive files in a matter of minutes, versus having an archiving group where people would take requests and find specific files on CD," said Capps Digital's Chris Carlock. "Now we have an interface that anybody here can access to search and retrieve files from any location. And they can see a thumbnail of that file."

Capps Digital also gained a new revenue source by creating customized websites where 


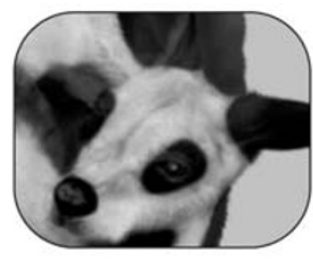

Figure 7: Using a DAM system to search for images increases agency productivity clients access, review, download and upload their assets.

"Each customer wants to look at something personalized for them. Now we can quickly develop personalized sites and create custom online storage solutions with custom coding that gives the client a site with a unique look, feel and shopping cart," Carlock said.

\section{WHAT ARE YOU LOOKING FOR?}

Success stories aside, everyone agrees that the crux of a good DAM system is built on logical, file-naming criteria.

Like the Dewey Decimal system developed for US public libraries, an ad agency DAM system must have an intuitive, proprietary naming system so an agency's staff and clients can look at a file and immediately understand the aspects of it.

"The asset management system is only as good as the information that's put into it," said Capps Digital's Chris Carlock. "Keywords don't generate on their own. It has to start at the beginning of the workflow system with work in progress on the server, then go downstream from there."

In other words, adding metadata adds value to the digital shoebox. It shouldn't all be visual.

To preserve the consistency of the metadata that goes in, some sites find it necessary to

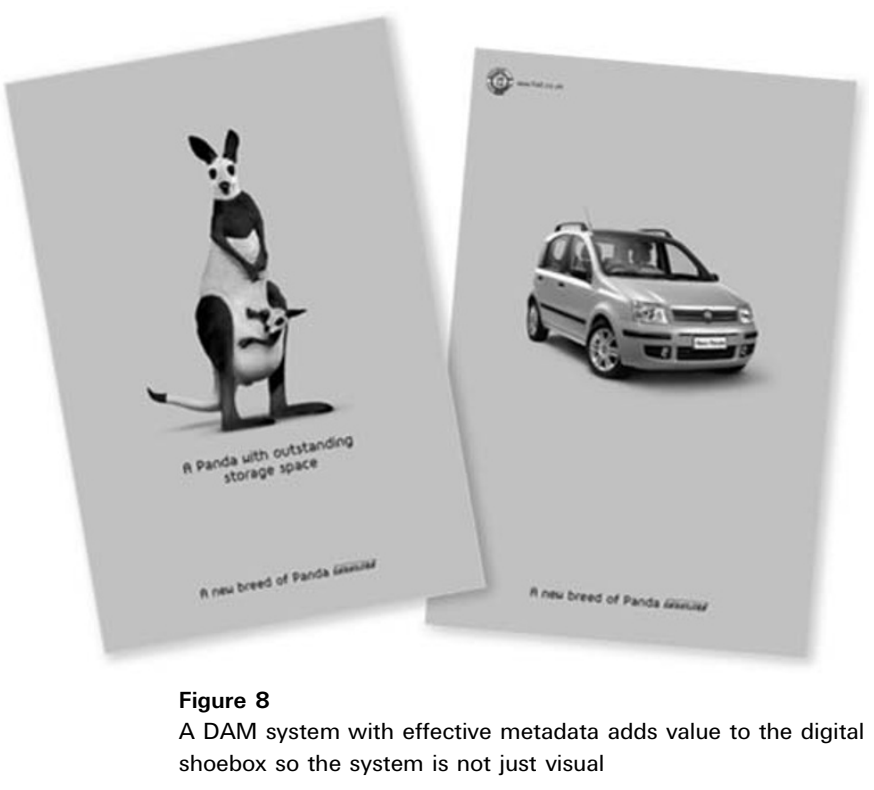

employ a full- or part-time librarian to input metadata. The beauty of the systems executed by the agencies profiled here, however, is that metadata are automatically ingested from the files themselves, along with XMP metadata and document linking information. Alternatively, agencies can choose to add more metadata from a separate interface, if they want.

"Databases and metadata are only good if you apply them," said McCann's Warren Vegas.

"Once you put a million assets into your system, no one goes back to enter metadata. You have to come up with a plan at the start that extracts information from the assets as they're ingested, and that takes into consideration what the account people are looking for, what the studio people are looking for, the client job number, etc."

A good place to begin is to ask the client exactly what they want in a personalized DAM system. That's the approach TracyLocke took with its client Grand Marnier.

TracyLocke's Director of Studio Services wrote a discovery survey for Grand Marnier that covered 15 questions, such as: What's important to you in a DAM? What are you looking to do? Do you want a button that says "Download JPEG?",

Then TracyLocke built the whole system according to the client's specifications.

"Instead of being locked into a box of an asset management system, we really noticed how viral this could get as far as of branching out into other possibilities," said TracyLocke's Fred Squeo.

\section{LOAD BALANCING AND CULTURAL BUY-IN}

One bonus of having an agency-wide DAM system that's widely used is the ability to balance workloads between offices.

"If our San Francisco office has more work than it can handle at a given moment, New York can take on extra work to help out and vice versa, and this system will certainly enhance the process," said McCann's Brad Mintz. "When one talks about load balancing, to me that means it's going to streamline our production process tremendously by allowing our people to get their work done faster and make them look better. Getting work done faster means more money." 


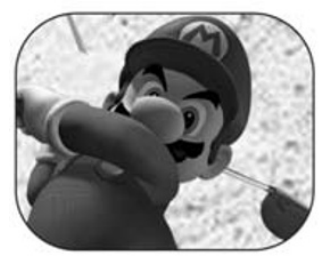

Figure 9: It takes minutes for new clients to become accustomed to utilizing a good DAM system
To ensure a cultural buy-in so his agency would feel comfortable using the DAM system, BBDO's Jd Michaels brought in Apple Computer so that his colleagues - some of whom were in their mid-60s — would first get familiar with programs like iPhoto, iMovie and iTunes.

"I put iPhoto, iMovie and iTunes on everyone's desktop so they would play with them and get them familiar with them in that way. One woman is 63 and now she can both search our DAM and mix and burn CDs! She is the first person you turn to when you need something," he said. "She learned, through looking for songs on iTunes, the basic principles of navigating any digital asset management system."

\section{DAM AS A PROFIT CENTER}

Part of the fear for some ad agencies in embracing DAM is the fact that it represents a new business model for advertising.

"We did a proposal last year on how by moving to a distributed model over the internet and no longer burning and shipping discs we could gain an efficiency savings of six figures for us and the client," said McCann's Warren Vegas. "For us, the big savings revolve around efficiency. We will still charge for doing something but the man hours for doing them is way lower because it allows the server and the distribution method to do most of the heavy lifting for us. And it's now usually correct because it's consistent."

The new business model that DAM presents boils down to more work with fewer people.

"In terms of the business model, we are working faster and we are working smarter. We're able to handle more work, and I have not asked for one more employee," said BBDO's Jd Michaels.

In a nutshell, a good DAM system is something an ad agency puts in once, then leverages over and over for clients on opposite sides of the globe.

"With today's technology, the geography of your office means nothing. It's the technology that you have. We are in Wilton, Connecticut, a small suburb 45 miles outside New York City, but we service our Pepsi International client throughout the Mideast, Asia, Europe," said TracyLocke's Fred Squeo. "That we are managing all the assets for Pepsi International out of our server in Wilton, Connecticut is a fact that really speaks for itself. Fifty gigabytes were downloaded last month off the Pepsi databank and our server didn't even break a sweat."

\section{References}

1 This remark, and all others cited in this paper, are sourced from personal interviews conducted on behalf of Xinet, Inc.

2 Moon, M. and Warwick, J. (2004) Business Case for Marketing Content Repositories in the Enterprise, GISTICS Incorporated, Oakland. 